\title{
EFFICACY OF R-ENDO AND E3-REROOT RETREATMENT ROTARY NITI SYSTEMS IN INTRACANAL FILLING MATERIAL REMOVAL
}

\author{
Tarek Medhat Elsewify* and H. M. Elhalaby**
}

\begin{abstract}
Aim: To compare the effectiveness of R-Endo and E3-ReRoot retreatment rotary files in filling material removal and operating time.

Materials and Methods: Twenty extracted distobuccal roots of maxillary first molars were decoronated to a standard length of $12 \mathrm{~mm}$. Root canal preparations were done using Fanta Blue (Fanta; ShangHai, China) till 0.04/25. Matching gutta percha cones of 0.04/25 were used with Adseal resin sealer (Meta Biomed, Chungcheongbuk-do, Republic of Korea) in warm vertical compaction technique. Teeth were left in an incubator at $37^{\circ} \mathrm{C}$ and $100 \%$ humidity for 30 days. Cone beam computed tomographic images of all roots were obtained to confirm three-dimensional filling of the root canal space. Roots were divided into two groups according to the file used in retreatment; group A using R-Endo (Micro-Mega, Besancon, France) and group B using E3-ReRoot (IMD; ShangHai, China). Time required to remove the filling material was recorded in seconds. Teeth were then split into two halves using hammer and chisel and remaining filling material was calculated using stereomicroscope at $4 \mathrm{X}$ original magnification. Statistical analysis was performed using One-Way ANOVA and significance level was set at 0.05 .
\end{abstract}

Results: E3-ReRoot was shown to be significantly more effective than R-Endo in intracanal filling removal. No significant difference was shown between both systems in the time needed to reach the working length.

Conclusion: E3-ReRoot was more effective in intracanal filling removal although both systems failed to totally remove gutta percha and sealer remnants from the root canals.

KEYWORDS: E3-ReRoot, remaining filling material, retreatment, R-Endo.

* Endodontic Department, Faculty of Dentistry, Ain Shams University, Cairo, Egypt

** Endodontic Department, Faculty of Dentistry, Assuit University, Assuit, Egypt 


\section{INTRODUCTION}

Total intracanal filling removal is deemed mandatory during endodontic retreatment to allow for adequate disinfection of the root canal system followed by apical and coronal seal ${ }^{(1)}$. An ideal retreatment instrument should allow complete removal of filling material in a short duration, with no alteration of the root canal space, no instrument separation and no apical extrusion of debris (2). Until now, no retreatment technique can effectively possess all these criteria ${ }^{(3-6)}$.

Many rotary instruments have been introduced with different design features; cross section, rake angle, radial lands and various tapers, to aid in nonsurgical retreatment. Conventionally, the removal of gutta percha using rotary instrumentation is a time saving process, safe and easy technique.

Some studies have shown multiple-file systems and single-file systems to be equally effective in root canal filling removal ${ }^{(7,8)}$. Retreatment files have been designed with active tips and more aggressive cutting, but their efficiency was still comparable to conventional files in root canal filling removal ${ }^{(9)}$.

The R-Endo system is composed of 4 instruments; $\operatorname{Re}$ (size 25, 0.12 taper) to flare the first few millimeters of the canal and 3 files (ie, R1, R2, and R3) dedicated to each root canal third to a size of 25 with $0.08,0.06$, or 0.04 tapers, respectively. An optional finishing file Rs (size 30, 0.04) is available if needed. The files have a triangular cross-section with three equally-spaced cutting edges and no radial land. The tip of the files is claimed to be inactive $^{(10)}$.

In a comprehensive literature review, no study examining the retreatment efficacy of the E3ReRoot retreatment file (IMD; ShangHai, China) could be found. According to the manufacturer, the instruments are made of $\mathrm{X}$ wire, austenitic at room temperature (11). They show a convex triangular cross-section with three cutting edges and large core with a progressively increasing pitch along the blades. E3-ReRoot file system is composed of five files; (Opener); size 22, 0.11 taper, for coronal flaring and three files comparable to R-Endo (R1, R2, and R3); size 25 with $0.08,0.06$, and 0.04 tapers, respectively. An optional R4 (size 30, 0.04) is also available.

Therefore, the aim of this study was to investigate the efficacy of R-Endo and E3-ReRoot retreatment instruments in root canal filling material removal and the operating time.

\section{MATERIALS AND METHODS}

\section{Sample selection}

Twenty distobuccal roots of human maxillary first molars were used in this study. Roots with open apices, resorptive defects, root fillings, caries, calcifications, cracks, and teeth with an initial apical diameter greater than size \#10 K-file were excluded. Roots were randomly divided into two main groups $(\mathrm{n}=10)$ according to the file used in retreatment procedure.

\section{Root Canal Preparation and Obturation}

Decoronation was done for all teeth standardizing root length to $12 \mathrm{~mm}$ and patency was checked using a \#10 manual K-file (Mani INC, Tochigi, Japan). The working length was set $0.5 \mathrm{~mm}$ short to the apical foramen.

Root canals were prepared using rotary files Fanta Blue (Fanta; ShangHai, China) till 0.04/25. Irrigation was done with $5 \mathrm{~mL}$ of $2.5 \%$ sodium hypochlorite and final flush using $5 \mathrm{ml}$ of EDTA $17 \%$ using a 27 gauge needle. Root canals were dried using paper points \#25. Matching gutta percha cones of 0.04/25 were used with Adseal resin sealer (Meta Biomed, Chungcheongbuk-do, Republic of Korea) in warm vertical compaction.

CBCT images were taken to confirm that the root canal filling quality was clinically acceptable. Roots were stored in $100 \%$ humidity at $37^{\circ} \mathrm{C}$ for 30 days. 


\section{Retreatment Procedures}

Web-based algorithm (www.random.org) was used to randomly allocate both groups $\mathrm{A}$ and $\mathrm{B}$ to the two retreatment files tested; group A for R-Endo (Micro-Mega, Besancon, France) and group B for E3-ReRoot retreatment file (IMD; ShangHai, China).

For both groups, R1 and R2 were used to one third and two thirds of the working length respectively. R3 was then used to the full working length $(12 \mathrm{~mm})$ in a circumferential motion. All files were used at a speed of $350 \mathrm{rpm}$ and a torque of $1.5 \mathrm{Ncm}$ using TriAuto mini (J Morita Corp., Japan).

All retreatment procedures were performed by a single endodontist (second author) using a dental operating microscope (Zumax, Suzhou New District, China). Retreatment was performed by instrumentation through the gutta percha, aiming to remove all the filling material and reach the working length. Once the working length was reached, 5 vertical strokes were applied along the entire canal length by brushing against the canal walls.

At the end of the procedure, patency was confirmed using a \#15 manual K-file. Irrigation was performed during instrumentation using $5 \mathrm{~mL}$ of sodium hypochlorite $2.6 \%$ for each root.

\section{Time required to reach the working length}

Total time required to reach the working length was recorded by a digital stopwatch (Timex, Middlebury, CT, USA) in seconds.

\section{Evaluation of the Remaining Filling Material}

Longitudinal grooves were cut in each root using a low-speed diamond disc. Each root was vertically split using hammer and chisel into two halves. Both halves were examined using a stereomicroscope. Digital images of each half were captured at $4 \mathrm{x}$ original magnification using a digital camera (DP-70; Olympus, Tokyo, Japan) attached to the microscope. Calculation of the remaining filling material was done using image $\mathrm{J}$ software (1.42a/ Java 1.6.0-10 image analyzer software). Each root canal was divided into thirds; coronal, middle, and apical. Percentage of the remaining filling material to the total canal area was calculated.

\section{Statistical Analysis}

Statistical analysis was performed using statistical package for social sciences (IBM SPSS Statistics for Windows, Version 25.0. Armonk, NY). Significance was analyzed by one-way ANOVA. Data were expressed by mean and standard deviation and $\mathrm{P}<0.05$ was considered as statistically significant.

\section{RESULTS}

\section{Intracanal filling material removal}

Means of percentages and standard deviations of remaining intracanal filling material in the different canal thirds in each group are shown in Table 1. Both techniques failed to totally remove intracanal filling. Considering the whole root canal and each root third individually, E3-ReRoot was shown to be more effective than R-Endo in intracanal filling removal with a statistically significant difference $(\mathrm{P}<0.05)$ as shown in table 1 and figures 1 and 2. The middle third showed the least amount of remaining intracanal filling followed by the apical third then the coronal third with a statistically significant difference.

No instrument separation occurred for both groups; yet, R-Endo group has shown ledges in the canals apically in five samples as shown in figure 3 .

\section{Time required to reach the working length}

There was no significant difference between R-Endo instruments $(189.333 \pm 75.706)$ and E3ReRoot instruments $(153 \pm 20.630)$ in removing gutta percha from root canals as shown in table 2 . 
TABLE (1) Mean and standard deviation values of the calculated percentage of remaining gutta percha to the total area of the root canal for both groups.

\begin{tabular}{|c|c|c|c|}
\hline & $\begin{array}{c}\text { R-Endo } \\
(\text { Group A) }\end{array}$ & $\begin{array}{c}\text { E3-ReRoot } \\
(\text { Group B) }\end{array}$ & P value \\
\hline Coronal & $11.735 \pm 2.511^{\mathrm{aA}}$ & $5.282 \pm 2.591^{\mathrm{bA}}$ & $0.001379^{*}$ \\
\hline Middle & $0.612 \pm 0.002^{\mathrm{aB}}$ & $0.023 \pm 0.016^{\mathrm{bB}}$ & $<0.00001^{*}$ \\
\hline Apical & $1.842 \pm 0.474^{\mathrm{aC}}$ & $0.483 \pm 0.025^{\mathrm{bC}}$ & $<0.00001^{*}$ \\
\hline Root Canal & $6.162 \pm 1.937^{\mathrm{a}}$ & $2.126 \pm 0.885^{\mathrm{b}}$ & $0.00092^{*}$ \\
\hline
\end{tabular}

Different lower case letters in the same row indicate statistically significance difference. Different upper case letters in the same column indicate statistically significance difference. *; significant $(p<0.05), n s$; non-significant $(p>0.05)$

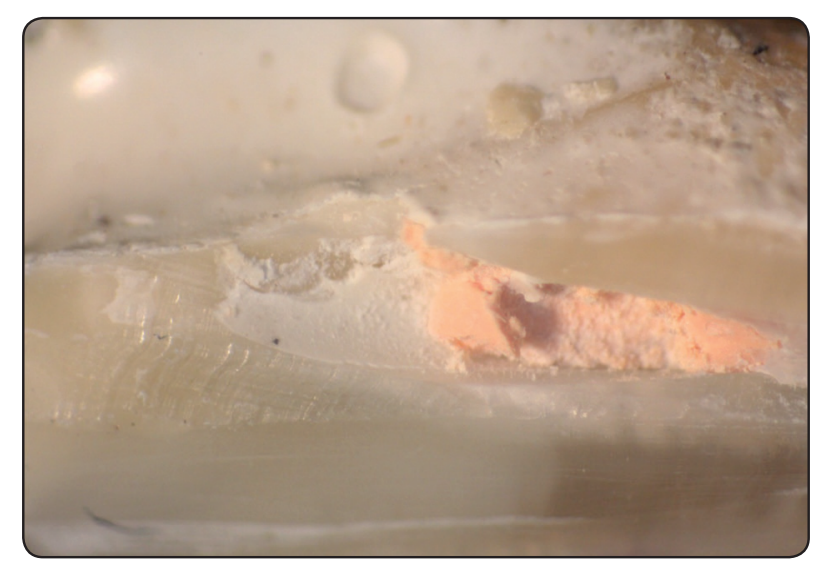

Fig. (1) Stereomicroscopic representative image of considerable amount of remaining intracanal filling in the coronal third, R-Endo group.

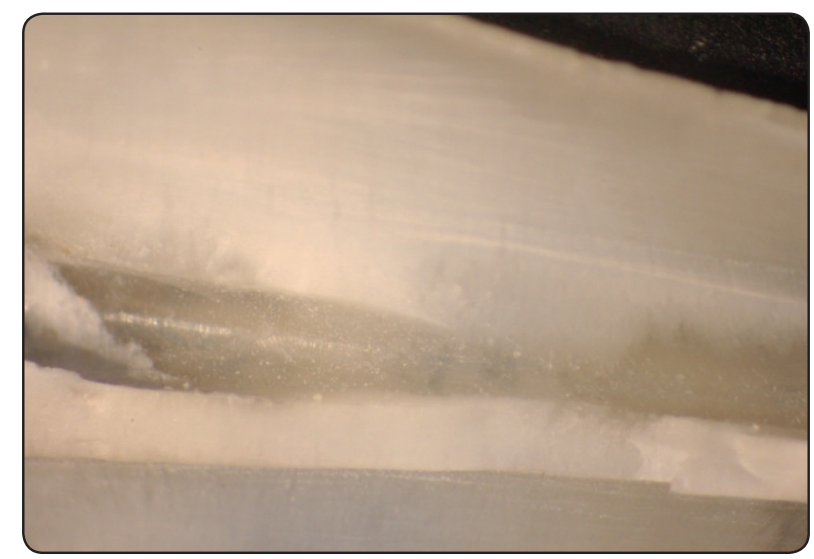

Fig. (2) Stereomicroscopic representative image of minute amount of remaining intracanal filling in the middle third, E3-ReRoot group.

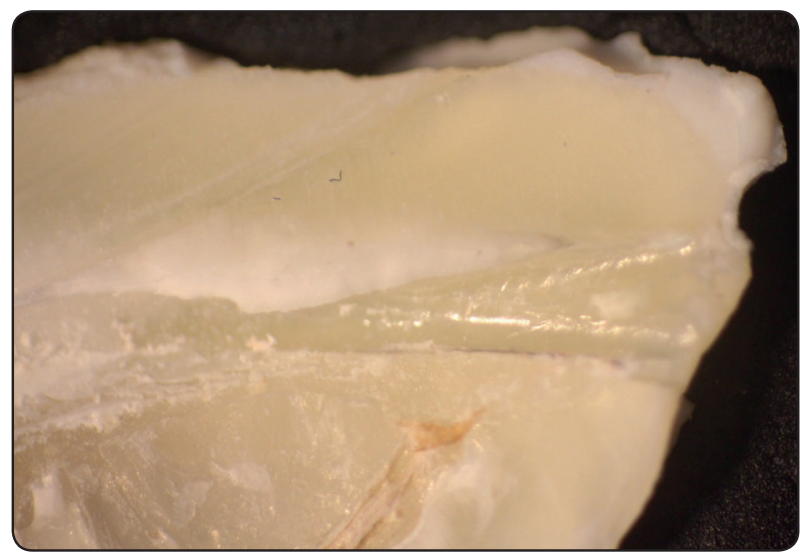

Fig. (3) Stereomicroscopic representative image of apical ledge from R-Endo group.

TABLE (2) Mean and standard deviation values of the preparation time (in seconds) needed to reach the working length for both groups.

\begin{tabular}{|c|c|c|c|}
\hline & $\begin{array}{c}\text { R-Endo } \\
\text { (Group A) }\end{array}$ & $\begin{array}{c}\text { E3-ReRoot } \\
\text { (Group B) }\end{array}$ & P value \\
\hline $\begin{array}{c}\text { Preparation } \\
\text { Time }\end{array}$ & $189.333 \pm 75.706^{\mathrm{a}}$ & $153 \pm 20.630^{\mathrm{a}}$ & $0.283163^{*}$ \\
\hline
\end{tabular}

Different letters in the same row indicate statistically significance difference.

*; significant $(p<0.05), n s ;$ non-significant $(p>0.05)$

\section{DISCUSSION}

Intracanal filling removal is an essential step in retreatment of failed root canal cases. It allows for elimination of the underlying cause of failure such as necrotic tissue or persistent bacteria ${ }^{(12,13)}$.

Distobuccal roots of maxillary molars were selected for the current study because these canals are often narrow and curved presenting technical challenge during cleaning and shaping rather than straight wide canals.

Decoronation of the distobuccal roots allowed for standardization of the study eliminating other variables including coronal morphology, coronal access, and access to root canals ${ }^{(14)}$. 
Removal of the smear layer followed by warm vertical compaction of gutta percha was used to ensure more homogeneous filling rather lateral condensation that entraps pools of sealer between gutta percha points and poor condensation in the apical third ${ }^{(15)}$.

Remaining intracanal filling can be evaluated by longitudinal sectioning ${ }^{(16,17)}$, radiographic assessment ${ }^{(14)}$, clearing technique ${ }^{(18)}$ and micro-computed tomography scan ${ }^{(19)}$. Each technique has its advantages and limitations. Longitudinal sectioning was performed in this study despite the fact that it may displace filling material remnants during sectioning ${ }^{(14)}$ as it allows for direct visualization, magnification and calculation of the remaining filling material.

Manufacturers' recommendations of speed and torque were followed. Low torque increases tactile sensation allowing for better control of the instrument and less procedural errors ${ }^{(20)}$ which is necessary during retreatment of narrow curved distobuccal roots of maxillary molars.

Low rotation speed was also used to mimic clinical situations. Although higher speed yield faster retreatment preparation, more procedural errors such as ledging, zipping, perforations and instrument separation are probable ${ }^{(21)}$.

Rotary retreatment instruments do not need chemical softening of gutta percha using solvents as they plasticize gutta percha by frictional heat. Solvent will create a thin gutta percha film on the dentinal wall compromising the antibacterial action of the irrigants used ${ }^{(22)}$.

Both systems failed to totally remove the intracanal filling from all root canals, consistent with previous studies ${ }^{(19,22,23)}$. E3-ReRoot was significantly more effective than R-Endo in intracanal filling removal from the whole root canal and from each root canal third alone. This finding cannot be directly compared to earlier studies because none could be found in the literature. As both systems share the same design features, the superior results of E3-ReRoot could be attributed to the $\mathrm{X}$ wire used with superior cutting efficacy.

Analyzing root canal thirds, the coronal third showed the highest percentage of remaining intracanal filling compared to the middle and apical thirds. This could be simply attributed to the use of R1, R2, and R3 only without the orifice opener with greater taper. Therefore, the used files did not contact the flared coronal third and did not remove the filling material even with circumferential movement. Another logic explanation is the oval shape cross section of the canal coronally in the distobuccal roots of maxillary molars which made more difficult for the retreatment file to contact all canal walls.

The middle third showed the lowest percentage of remaining intracanal filling. This could be attributed to the similar size and taper of the files used in preparation and retreatment. Fanta Blue 0.04/25 was used in preparation followed by retreatment files ending with R3 0.04/25 as well. This resulted in total contact between the retreatment files used and the dentinal wall in the middle third resulting in the better cleaning.

The apical third showed higher percentage of remaining intracanal filling than the middle third. These results are in agreement with previous studies ${ }^{(12,13,24)}$. This could be explained on the basis of higher anatomical variability and difficulty of instrumentation in this area. Distobuccal roots of maxillary molars show curvatures in many planes in the apical third which makes it impossible to direct NiTi instruments against entire root canal walls ${ }^{(12,13)}$.

E3-ReRoot was shown safer than R-Endo for retreatment as no procedural errors such as zipping, ledge, perforation or instrument separation occurred in group B. R-Endo group has shown ledges in the canals apically in $30 \%$ of the samples. This could 
be attributed to the rigid retreatment files used in narrow curved distobuccal root canals of maxillary molars.

Preparation time needed to reach the working length did not differ significantly for both systems. This is a logic finding as both systems are comparable in size, taper, design, kinematics, torque, and number of files.

Under the experimental conditions, E3-ReRoot system was significantly more effective than $\mathrm{R}$-Endo system in intracanal filling removal. Both systems failed to totally remove the entire intracanal filling. No difference between both systems in the preparation time needed to reach the working length.

\section{REFERENCES}

1. Virdee SS, Thomas MB. A practitioner's guide to guttapercha removal during endodontic retreatment. Br Dent J 2017; 222:251-7.

2. Adham A. Azim, Howard H. Wang, Mohamed Tarrosh, Katharina A. Azim, MA,,and Lucila Piasecki. Comparison between Single-file Rotary Systems: Part 1-Efficiency, Effectiveness, and Adverse Effects in Endodontic Retreatment. J Endod 2018;44:1720-1724.

3. Mangalam S, Rao CV, Lakshminarayanan L. Evaluation of apically extruded debris and irrigant using three instrumentation techniques. Endodontology 2002;14:19-23.

4. Parirokh M, Jalali S, Haghdoost AA, Abbott PV. Comparison of the effect of various irrigants on apically extruded debris after root canal preparation. J Endod 2012;38: 196-9.

5. Vande Visse JE, Brilliant JD. Effect of irrigation on the production of extruded material at the root apex during instrumentation. J Endod 1975;1:243-6.

6. Yeter KY, Evcil MS, Ayranci LB, Ersoy I. Weight of apically extruded debris following use of two canal instrumentation techniques and two designs of irrigation needles. Int Endod J 2013; 46:795-9.

7. Alves FR, Marceliano-Alves MF, Sousa JC, et al. Removal of root canal fillings in curved canals using either reciprocating single- or rotary multi-instrument systems and a supplementary step with the XP-Endo Finisher. J Endod 2016;42:1114-9.
8. Monguilhott Crozeta B, Damiao de Sousa-Neto M, Bianchi Leoni G, et al. A microcomputed tomography assessment of the efficacy of rotary and reciprocating techniques for filling material removal in root canal retreatment. Clin Oral Investig 2016; 20:2235-40.

9. Yilmaz F, Koc C, Kamburoglu K, et al. Evaluation of 3 different retreatment techniques in maxillary molar teeth by using micro-computed tomography. J Endod 2018; 44:480-4.

10. Fenoul G, Meless GD, Perez F. The efficacy of R-Endo rotary NiTi and stainless-steel hand instruments to remove gutta-percha and Resilon. Int Endod J 2010;43: 135-41.

11. E3-ReRoot brochure at http://www.imdmedical.com/\#/ Products/MPro\%203\%20Files\%20System Accessed March 2019.

12. Hülsmann M and Bluhm V. Efficacy, cleaning ability and safety of different rotary NiTi instruments in root canal retreatment. Int Endod J. 2004;37(7):468-76.

13. Shirrmeister J, Wrbas KT, Schneider F, Altenburger M, Hellwing E. Effectiveness of a hand file and three nickeltitanium rotary instruments for removing guttapercha in curved root canals during retreatment. Oral Surg Oral Med Oral Pathol Oral Radiol Endod; 2006; 101, 542-7.

14. Ferreira J.J., Rhones, J.S., Pitt Ford, T.R. The efficacy of gutta-percha removal using ProFiles. Int Endod J. 2001;34:267-274

15. Nguyen NT. Obturation of the root canal system. In: Cohen, S Burns, RC, ed. Pathways of the Pulp,4th edn. St. Louis, USA: Mosby, pp.183-94.

16. Kosti E, Lambrianidis T, Economides N, and Neofitou C. Ex vivo study of the efficacy of H-files and rotary Ni-Ti instruments to remove gutta-percha and four types of sealer. Int Endod J. 2006;39 (1):48-54.

17. Zmener O, Pameijer H, Banegas G. Retreatmentefficacy of hand versus automated instrumentation inoval-shaped root canals: an ex vivo study. Int Endod J2006; 39:521-526.

18. Schirrmeister F, Meyer M, Hermanns P, Altenburger J, and Wrbas T. Effectiveness of hand and rotary instrumentation for removing a new synthetic polymer-based root canal obturation material (Epiphany) during retreatment. Int Endod J. 2006;39(2):150-6.

19. Barletta B, Rahde M, Limongi O, Moura A, Zanesco C, Mazocatto G. In vitro comparative analysis of 2 mechanical techniques for removing gutta-percha during retreatment. J Can Dent Assoc. 2007;73(1):65. 
20. Gambarini G. Rationale for the use of low-torque endodontic motor in root canal instrumentation. Endodontics $\&$ dental traumatology, 2000; 16(3):95-100.

21. Ounsi HF, Salameh Z, Al-Shalan T, et al. Effect of clinical use on the cyclic fatigue resistance of protaper nickeltitanium rotary instruments. J Endod, 2007; 33, 737-41.

22. Wilcox R, Juhlin J. Endodontic retreatment of Thermafil versus laterally condensed gutta-percha. J Endod; 1994; 20(3):115-7.
23. Masiero A and Barletta F. Effectiveness of different techniques for removing gutta-percha during retreatment. Int Endod J, 2005; 38, 2-7.

24. Gergi R and Sabbagh C. Effectiveness of two nickel-titanium rotary instruments and a hand file for removing guttapercha in severely curved root canals during retreatment: an ex vivo study. International Endodontic Journal; 2007; 40, 532-537. 